\title{
Uji Kelayakan Modul Animalia Kontekstual Berbasis Level of Inquiry untuk Siswa SMA di Wilayah Pesisir
}

\author{
Afifah Eka Putri a, ${ }^{*}$, Murni Ramli b, 2, Suciati ${ }^{\text {c, } 3}$ \\ a,b,c Pendidikan Biologi FKIP, Universitas Sebelas Maret, Jalan Ir. Sutami 36A Kentingan, Surakarta 57126, Indonesia \\ ${ }^{1}$ afifahekaputri@student.uns.ac.id*; ${ }^{2}$ mramlim@staff.uns.ac.id; ${ }^{3}$ suciati.sudarisman@yahoo.com \\ *korespondensi penulis
}

\begin{abstract}
ABSTRAK
Pembelajaran materi Animalia secara kontekstual menjadi salah satu solusi untuk mempermudah memahami materi Animalia. Selain itu, penggunaan modul dan model pembelajaran Level of Inquiry (LoI) diharapkan dapat membantu mempelajari materi Animalia. Tujuan penelitian ini, yaitu untuk mengetahui: (1) karakteristik modul Animalia kontekstual berbasis LoI, (2) kelayakan modul Animalia kontekstual berbasis LoI. Metode penelitian menggunakan sembilan langkah model penelitian dan pengembangan Borg \& Gall. Data yang diperoleh yaitu data hasil validasi ahli, validasi praktisi pendidikan, dan hasil uji coba dianalisis secara deskriptif kuantitatif. Hasil penelitian dan pengembangan menunjukkan bahwa modul Animalia kontekstual berbasis LoI dikembangkan sesuai sintaks LoI. Modul Animalia kontekstual berbasis LoI dinyatakan layak oleh ahli materi sebesar 85\%, ahli pengembangan desain dan keterbacaan modul 91,07\%, ahli perangkat pembelajaran $82 \%$, ahli bahasa $81 \%$, praktisi pendidikan $89,42 \%$, dan siswa $87,67 \%$. Hasil uji operasional diperoleh bahwa nilai rata-rata posttest kelas eksperimen lebih tinggi $(73,34)$ daripada kelas kontrol $(65,93)$ dan terdapat perbedaan signifikansi dengan nilai signifikansi 0,02.
\end{abstract}

Kata kunci: animalia, kontekstual, level of inquiry, modul sains

\begin{abstract}
Feasibility test animalia contextual module based on level of inquiry for senior high school students' in coastal area. Contextual learning were one of solutions to facilitate Animalia's subject matter. Furthermore, module and Level of Inquiry Model were expected to facilitate in learning Animalia subject matter. This study aim to determine (1) characteristics Animalia contextual module based on LoI, and (2) feseability of Animalia contextual module based on LoI. The research used nine step of Borg \& Gall's research and development model. The data were collected from expert validation, educational practioner validation, and operasional test. The data were analyzed quantitative descriptive. Results of research and development show that the LoI-based contextual Animalia modules developed according to the syntax of the LoI. Module-based contextual Animalia LoI declared eligible by subject matter experts by $85 \%$, expert module development, design and readability of $91.07 \%$, a learning device $82 \%$, $81 \%$ linguists, education professionals $89.42 \%$, and $87.67 \%$ students. The operational test results obtained that the average value of the experimental class posttest is higher (73.34) than the control class $(65,93)$ and there is significance difference with the significance value of 0,02 .
\end{abstract}

Keyword: animalia, contextual, level of inquiry, module sains

Copyright (C) 2017 Universitas Ahmad Dahlan. All Right Reserved

\section{Pendahuluan}

Perbaikan dalam proses pembelajaran perlu dilakukan untuk meningkatkan kualitas pendidikan. Banyak komponen di dalam proses pembelajaran yang dapat mempengaruhi hasil belajar, antara lain: tujuan, bahan atau materi yang dipelajari, strategi pembelajaran, siswa dan guru sebagai subjek belajar, media pembelajaran dan penunjang proses pembelajaran (Sugandi dalam Praptiwi, Sarwi, \& Handayani, 2012) Komponen-komponen tersebut saling terkait satu sama lain sehingga melemahnya satu komponen akan menghambat pencapaian tujuan pembelajaran secara maksimal.

Masalah dalam proses pelaksanaan pembelajaran memberikan dampak pada penguasaan materi biologi siswa, khususnya pada materi-materi yang bersifat konseptual. Hal tersebut dapat dilihat dari data daya serap hasil Ujian Nasional khususnya pada materi Animalia di SMA A Kecamatan Tanjungsari Tahun Pelajaran 2013/2014 masih rendah, yaitu sebesar 36,11\%.

Rendahnya penguasaan konsep siswa pada materi Animalia didukung hasil wawancara dengan guru yang menunjukkan bahwa materi Animalia merupakan salah satu materi yang sulit bagi guru maupun siswa. Materi Animalia diajarkan guru dengan cara ceramah dan mengambil sub-sub materi yang sering digunakan dalam ujian. Berdasarkan pengakuan guru, hal tersebut dilakukan karena keterbatasan waktu yang tersedia. Hasil wawancara dengan siswa menunjukkan bahwa materi Animalia sulit untuk dihafalkan karena banyaknya konsep yang harus dipelajari dan adanya nama-nama ilmiah yang asing bagi siswa.

Materi Animalia bersifat menarik, karena contoh Animalia banyak dijumpai di lingkungan sehari-hari sehingga pembelajaran materi Animalia 
dapat dilakukan secara kontekstual. Kontekstual yang dimaksud yaitu mengaitkan materi dengan situasi dunia nyata, memotivasi siswa agar dapat menghubungkan antara pengetahuan dan penerapannya dalam kehidupan sehari-hari (National Conference on Teacher Quality dalam Kamariah \& Rashid, 2011). Pelajaran yang diperoleh siswa akan lebih berarti ketika siswa mempelajari materi Animalia yang disajikan melalui konteks kehidupan dan menemukan arti, relevansi, serta manfaat di dalam proses pembelajaran sehingga menjadi lebih berarti dan menyenangkan. Konteks kehidupan yang dimaksud adalah lingkungan sekitar siswa di SMA A Kecamatan Tanjungsari, yaitu potensi lokal di Kabupaten Gunungkidul yang dapat dijadikan sumber belajar. Namun, potensi lokal tersebut belum dimanfaatkan oleh guru.

Salah satu potensi lokal di Kabupaten Gunungkidul yang belum banyak dimanfaatkan untuk kegiatan belajar adalah ekosistem pesisir selatan Gunungkidul. Hasil identifikasi terhadap potensi lokal pesisir selatan Gunungkidul yaitu adanya keragaman hewan khas daerah pesisir baik invertebrata maupun vertebrata. Keanekaragaman hewan yang terdapat di daerah pantai selatan Gunungkidul dapat dimanfaatkan sebagai sumber belajar pada materi Animalia.

Keberhasilan pembelajaran dipengaruhi juga oleh faktor pendukung, salah satunya adalah bahan ajar. Bahan ajar yang dipakai di SMA A Kecamatan Tanjungsari belum mendukung kegiatan belajar biologi siswa karena bahan ajar masih berorientasi produk, sehingga belajar biologi terkesan sebagai belajar menghapal dan tanpa melalui proses berpikir maupun bernalar. Apabila ditinjau dari aspek penyajian, kurang menarik karena terlalu banyak deskripsi materi yang panjang dan sedikit gambar. Bahan ajar belum menampilkan gambar-gambar contoh yang memudahkan siswa dalam mempelajari materi Animalia. Gambar yang disajikan bukan gambar contoh yang sebenarnya tetapi hanya skema atau animasi. Beberapa gambar berukuran kecil dan tidak jelas. Pada aspek kelayakan isi, bahan ajar kurang sesuai antara cakupan materi dengan kompetensi dasar, tujuan pembelajaran, dan urutan sub topik. Apabila ditinjau dari aspek bahasa, bahan ajar kurang disesuaikan dengan perkembangan siswa dan kurang memotivasi siswa.

Berdasarkan permasalahan tersebut maka, diperlukan bahan ajar yang dapat memfasilitasi siswa untuk belajar mandiri, dan dapat membantu siswa menguasai konsep materi Animalia secara menyeluruh. Modul merupakan bahan ajar cetak yang berisi rangkaian kegiatan belajar yang direncanakan, dirancang, dan dilengkapi petunjuk untuk belajar sendiri sebagai penghubung pengetahuan siswa dengan objek yang dipelajari (Mulyasa, 2005; Prastowo, 2012; Sukirman, 2012). Modul yang berorientasi sains hendaknya memberikan peluang kepada siswa untuk dapat menguasai produk sains, seperti konsep-konsep dan menggunakan metode ilmiah untuk memecahkan masalah-masalah sains (Toharudin, Hendrawati, \& Rustaman, 2011)

Modul dapat disisipi strategi, metode, atau model pembelajaran yang dapat menunjang siswa belajar materi Animalia. Salah satu model pembelajaran yang berpotensi membantu siswa untuk mempermudah mempelajari materi Animalia adalah model inquiry karena mempunyai karakteristik mengutamakan proses penyelidikan dan penemuan fakta (Oral, 2012). Wenning (2011) mengemukakan bahwa pembelajaran menggunakan model inquiry yang disebut sebagai levels of inquiry (LoI), yaitu discovery learning, interactive demonstration, inquiry lesson, inquiry lab, dan hypothetical inquiry. Setiap level inquiry memiliki perbedaan, terutama pada peran kontrol guru di kelas dan ketercapaian intelektual yang diharapkan (Wenning, 2011).

Melalui level-level dari model pembelajaran inquiry, siswa berlatih untuk mengemukakan pertanyaan dan mengumpulkan bukti-bukti dari berbagai sumber untuk menjawab permasalahan yang ditemukan, serta mempertanggungjawabkan secara ilmiah atas kesimpulan yang telah dibuat. Model pembelajaran inquity dapat membangun konsep siswa terhadap materi Animalia melalui pengalaman belajar (Keogh \& Stuart dalam Garbett, 2011). Hasil penelitian Suwondo, dkk. (2013) menunjukkan bahwa pemahaman dan aktivitas siswa dalam mempelajari materi invertebrata mengalami peningkatan dalam pembelajaran yang menggunakan model inquiry.

Berdasarkan uraian latar belakang tersebut, maka perlu dikembangkan modul pembelajaran biologi materi Animalia berbasis levels of inquiry (LoI) dengan memanfaatkan potensi wilayah pesisir. Modul tersebut disusun secara sistematis sesuai potensi lokal dan berbasis inquiry sehingga siswa menguasai produk sains dan menggunakan metode ilmiah. Modul tersebut dapat mendorong siswa untuk menganalisis, memecahkan permasalahan berdasarkan fakta-fakta yang ditemukan sehingga diperoleh pemahaman konseptual (Rusche \& Jason, 2011). Modul berisi materi Animalia kelas X SMA dapat digunakan sebagai bahan belajar di kelas maupun mandiri. 


\section{Metode Penelitian}

Penelitian dan pengembangan menggunakan prosedur pengembangan (Borg \& Gall, 1983) yang dimodifikasi menjadi sembilan tahapan: 1) analisis kebutuhan, 2) perencanaan, 3) pengembangan produk awal, 4) uji coba lapangan awal, 5) revisi produk pertama, 6) uji coba lapangan skala kecil, 7) revisi produk kedua, 8) uji coba operasional, 9) revisi produk ketiga.

Tahap analisis kebutuhan meliputi studi literatur dan lapangan. Studi literatur meliputi mencari literatur mengenai materi Animalia yang diajarkan pada tingkat SMA, modul sains, pembelajaran kontekstual dan model LoI. Studi lapangan meliputi kegiatan untuk memperoleh informasi tentang kondisi pembelajaran melalui observasi dan wawancara; daya serap hasil UN Tahun Pelajaran 2013/2014; dan bahan ajar biologi melalui lembar analisis bahan ajar.

Tahap perencanaan digunakan sebagai dasar penyiapan rancangan awal penyusunan modul Animalia kontekstual berbasis LoI. Kegiatan yang dilakukan pada tahap perencanaan meliputi: menentukan indikator pembelajaran pada modul sesuai dengan Kurikulum 2013; menentukan urutan sub pokok bahasan materi Animalia yang dibahas dalam modul; penyusunan matrik kegiatan belajar modul dengan memasukkan tahapan dalam sintaks pembelajaran dari LoI; menyusun desain produk modul dengan cara membuat desain modul, mengumpulkan bahan-bahan pendukung seperti gambar, literatur, dan wacana.

Tahap pengembangan produk awal berpedoman pada perencanaan yang telah dibuat sebelumnya. Tahap pengembangan produk awal meliputi pembuatan desain modul sesuai dengan sintaks LoI sebagai model pembelajaran yang telah diintegrasikan dalam kegiatan belajar modul.

Tahap uji coba lapangan awal meliputi uji validasi ahli yang terdiri atas ahli materi, ahli media pembelajaran, ahli perangkat pembelajaran, serta ahli tata bahasa. Revisi produk pertama dilakukan berdasarkan hasil uji validasi ahli terkait kesesuaian materi, kesesuaian prosedur pengembangan desain dan keterbacaan modul, kesesuaian perangkat pembelajaran, dan kesesuaian bahasa yang digunakan.

Tahap uji coba lapangan skala kecil meliputi validasi perorangan praktisi pendidikan (guru biologi) dan uji kelompok kecil (siswa). Revisi produk kedua dilakukan berdasarkan hasil validasi praktisi pendidikan dan uji kelompok kecil sehingga mendapatkan bahan pertimbangan untuk memperbaiki produk modul hasil revisi pertama agar lebih layak digunakan dalam uji coba operasional.
Tahap uji coba operasional dilakukan untuk mengetahui keefektifan produk modul yang dikembangkan. Desain penelitian yang digunakan dalam uji coba operasional adalah control group postest only. Desain uji menggunakan dua kelas yaitu kelas kontrol dan kelas eksperimen. Subjek dalam uji coba operasional modul animalia kontekstual berbasis LoI adalah siswa kelas X SMA A di Kecamatan Tanjungsari. Jenis data yang diperoleh dari uji coba operasional berupa data kualitatif dan data kuantitatif. Analisis data kualitatif menggunakan analisis deskriptif, sedangkan data kuantitatif menggunakan uji prasyarat yaitu uji normalitas dan homogenitas serta uji verifikasi yaitu uji t. Revisi produk ketiga dilakukan berdasarkan hasil uji coba operasional. Informasi kualitatif dan hasil analisis digunakan untuk dasar pertimbangan untuk memperbaiki produk modul hasil revisi kedua sehingga didapatkan modul yang layak pakai.

\section{Hasil dan Pembahasan}

Modul Animalia kontekstual berbasis LoI disusun berdasarkan hasil analisis kebutuhan. Tahap perencanaan digunakan sebagai dasar penyiapan rancangan awal penyusunan modul Animalia kontekstual berbasis LoI. Pada tahap perencanaan dilakukan identifikasi materi Animalia, yaitu merangkum materi Animalia dari berbagai literatur untuk memperoleh gambaran dari apa saja yang akan dimasukkan dalam modul pembelajaran. Selanjutnya, penyusunan matrik modul dengan memasukkan tahapan dalam sintaks pembelajaran dari LoI yang terdiri dari lima tahapan. Langkah selanjutnya adalah menyusun desain produk modul dengan cara membuat desain modul, mengumpulkan bahanbahan pendukung seperti gambar, literatur, dan wacana.

Modul Animalia kontekstual berbasis LoI diuji kelayakannya melalui validasi ahli modul, yang terdiri atas: validasi ahli materi modul; validasi ahli media pembelajaran; validasi ahli perangkat pembelajaran; validasi ahli tata bahasa. Hasil validasi ahli modul seperti pada Tabel 1 .

Tabel 1. Hasil uji coba lapangan awal

\begin{tabular}{lcl}
\hline \multicolumn{1}{c}{ Ahli } & Skor $(\%)$ & Kualifikasi \\
\hline Materi & 85 & Sangat layak \\
Media pembelajaran & 91,07 & Sangat layak \\
Perangkat pembelajaran & 82 & Sangat layak \\
Tata bahasa & 81 & Sangat layak \\
\hline
\end{tabular}

Modul Animalia kontekstual berbasis LoI juga diuji oleh praktisi pendidikan dan kelompok kecil siswa dalam uji coba lapangan skala kecil. Hasil tahap uji coba lapangan skala kecil seperti Tabel 2. 
Tabel 2. Hasil uji coba lapangan skala kecil

\begin{tabular}{ccc}
\hline Validasi & Skor $(\%)$ & Kualifikasi \\
\hline Praktisi pendidikan & 89,42 & Sangat layak \\
Uji kelompok kecil & 87,67 & Sangat layak \\
\hline
\end{tabular}

Modul Animalia kontekstual berbasis LoI kemudian digunakan dalam proses pembelajaran biologi pada uji lapangan operasional. Hasil yang diperoleh dari posttest siswa di kelas eksperimen dan kontrol dapat dilihat pada Tabel 3.

Tabel 3. Data nilai posttest siswa pada kelas eksperimen dan kelas kontrol

\begin{tabular}{ccccc}
\hline $\begin{array}{c}\text { Data hasil } \\
\text { belajar } \\
\text { siswa }\end{array}$ & Kelas & $\begin{array}{c}\text { Nilai } \\
\text { maksi } \\
\text { mum }\end{array}$ & $\begin{array}{c}\text { Nilai } \\
\text { minimum }\end{array}$ & $\begin{array}{c}\text { Rata- } \\
\text { rata }\end{array}$ \\
\hline \multirow{2}{*}{ posttest } & $\begin{array}{c}\text { Eksperimen } \\
\text { Kontrol }\end{array}$ & $\begin{array}{c}93,00 \\
88,00\end{array}$ & 52,00 & 73,34 \\
& & & & 65,93 \\
\hline
\end{tabular}

Hasil uji prasyarat analisis parametrik (tabel 4) dilakukan sebelum dilakukan uji keterkaitan antara modul dengan kualitas pembelajaran.

Tabel 4. Hasil uji prasyarat analisis parametrik

\begin{tabular}{ccccc}
\hline Perlakuan & Uji & $\begin{array}{c}\text { Hasil } \\
\text { (sig.) }\end{array}$ & $\begin{array}{c}\text { Keputus } \\
\text { an }\end{array}$ & $\begin{array}{c}\text { Kesimpu } \\
\text { lan }\end{array}$ \\
\hline $\begin{array}{c}\text { Eksperimen } \\
\text { (X-B) }\end{array}$ & $\begin{array}{c}\text { Norma } \\
\text { litas }\end{array}$ & $\begin{array}{c}0,395> \\
0,05\end{array}$ & $\begin{array}{c}\text { Ho } \\
\text { diterima }\end{array}$ & $\begin{array}{c}\text { Distribusi } \\
\text { nilai } \\
\text { normal }\end{array}$ \\
$\begin{array}{c}\text { Kontrol } \\
\text { (X-D) }\end{array}$ & $\begin{array}{c}\text { Norma } \\
\text { litas }\end{array}$ & $\begin{array}{c}0,449> \\
0,05\end{array}$ & $\begin{array}{c}\text { Ho } \\
\text { diterima }\end{array}$ & $\begin{array}{c}\text { Distribusi } \\
\text { nilai } \\
\text { normal }\end{array}$ \\
Semua & Homo & $0,169>$ & Ho & $\begin{array}{c}\text { Nilai } \\
\text { kelas }\end{array}$ \\
genitas & 0,05 & diterima & homogen \\
\hline
\end{tabular}

Hasil uji keterkaitan antara modul dengan kualitas pembelajaran dapat dilihat pada tabel 5 .

Tabel 5. Hasil uji independent sample t-test

\begin{tabular}{lcccl}
\hline Variabel & $\mathbf{t}$ & Sig. & Keputusan & Kesimpulan \\
\hline Kelas & 5,137 & 0,023 & Ho ditolak & Ada \\
eksperimen & & $<$ & & perbedaan \\
dan & & 0,05 & & rerata kelas \\
kontrol & & & & eksperimen \\
& & & & dan kelas \\
& & & & kontrol \\
\hline
\end{tabular}

Modul Animalia kontekstual berbasis LoI diuji kelayakannya melalui tahap: a) Uji coba awal: validasi ahli materi modul; validasi ahli pengembangan, desain dan keterbacaan modul; validasi ahli perangkat pembelajaran; dan validasi ahli tata bahasa., b) Uji lapangan terbatas: praktisi pendidikan dan uji kelompok kecil. Pengujian kelayakan modul animalia kontekstual berbasis LoI oleh validator ahli sesuai dengan pendapat yang dikemukakan oleh Daryanto (2013) bahwa validasi dapat dilakukan dengan cara meminta bantuan ahli yang menguasai kompetensi yang dipelajari. Berdasarkan hasil uji validator, praktisi pendidikan, dan penerapan dalam pembelajaran, diperoleh karakteristik modul Animalia kontekstual berbasis LoI adalah sebagai berikut:

a) Modul Sains

Modul Animalia kontekstual berbasis LoI merupakan modul sains. Modul Animalia kontekstual berbasis LoI digunakan siswa untuk mempelajari dan menguasai produk dan proses sains melalui metode ilmiah (Toharudin et al., 2011).

b) Berbasis model LoI

Modul Animalia kontekstual berbasis LoI terdiri dari tiga level secara berurutan dimulai dari discovery learning, interactive demonstration, inquiry lesson. Masing-masing level memiliki lima sintaks dasar, yaitu observasi, manipulasi, generalisasi, verifikasi, dan aplikasi. Setiap sintaks pada masingmasing level mempunyai ketercapaian tujuan dan kontrol guru yang berbeda sehingga siswa mendapatkan pengalaman belajar yang berbeda pada setiap levelnya. Hal tersebut dapat membantu membiasakan siswa belajar secara inquiry dari level yang paling rendah hingga level yang tertinggi.

Masing-masing level inquiry mempunyai karakteristik yang berbeda dalam penjabaran sintaksnya. Level discovery learning mempunyai karakteristik pada keterlibatan aktif siswa untuk mengembangkan konsep berdasarkan pengalaman langsung. De Jong et al. (dalam Balım, 2009) menyatakan bahwa siswa mengkontruksi pengetahuan berdasarkan informasi baru dan data yang dikumpulkan dari kegiatan eksplorasi melalui discovery learning. Level discovery learning digunakan untuk kegiatan belajar 1 yang mempelajari ciri-ciri Animalia karena level discovery learning pengembangan pemahaman konsep didasarkan pada deskripsi dari suatu fenomena. Deskripsi dari fenomena tersebut diperoleh dari pengamatan terhadap fenomena. Untuk mempelajari ciri-ciri Animalia, pengamatan terhadap Animalia pun diperlukan agar siswa dapat mendeskripsikan ciricirinya. Oleh karena itu, level discovery learning sesuai untuk mempelajari subtopik ciri-ciri Animalia.

Level interactive demonstration mempunyai karakteristik melibatkan siswa dalam penjelasan dan pembuatan prediksi berdasarkan pengalaman pengetahuan sebelumnya melalui suatu demonstrasi. Pembuatan prediksi menuntun siswa aktif dalam proses berpikir dan bernalar sehingga memberikan kemungkinan siswa lebih memahami fenomena fisik dan proses penyelidikan (Mackovjaková \& Ješková, 2014). Level interactive demonstration digunakan untuk kegiatan belajar 2 yang mempelajari klasifikasi Animalia. Untuk mempelajari klasifikasi Animalia, siswa harus memahami ciri-ciri Animalia pada materi sebelumnya sehingga mampu membuat kunci determinasi untuk membantu dalam 
pengklasifikasian Animalia. Pembuatan kunci determinasi tersebut diawali dengan proses demonstrasi oleh guru, agar siswa membuat prediksi dan menerapkan mengenai cara mengklasifikasi Animalia sesuai pemahaman siswa dari proses demonstrasi.

Level inquiry lesson mempunyai karakteristik melibatkan siswa dalam mengidentifikasi prinsipprinsip ilmiah atau hubungan antarkonsep untuk membangun pengetahuan yang lebih rinci. Level inquiry lesson digunakan untuk kegiatan belajar 3 yang mempelajari peranan Animalia. Peranan Animalia dapat dipelajari setelah siswa memahami ciri-ciri Animalia dan klasifikasinya karena setiap jenis Animalia mempunyai peranan yang berbeda dalam kehidupan. Oleh karena itu, siswa perlu menghubungkan konsep yang sudah dipelajari sebelumnya untuk mengidentifikasi peranan Animalia dalam kehidupan.

c) Dikembangkan untuk materi Animalia

Materi Animalia dalam produk modul yang dikembangkan dibagi menjadi tiga subtopik, yaitu ciri-ciri Animalia, klasifikasi Animalia, dan karakteristik Animalia. Tiap subtopik membahas sembilan filum Animalia mulai dari porifera, cnidaria, platyhelminthes, nemathelminthes, annelida, mollusca, arthropoda, echinodermata, dan chordata. Pembahasan subtopik tersebut berbeda dari modul sebelumnya maupun bahan ajar yang digunakan di sekolah. Kelebihan dari urutan subtopik tersebut adalah siswa dapat langsung membandingkan persamaan ataupun perbedaan Animalia mulai dari yang paling sederhana hingga yang paling kompleks. Pada modul sebelumnya maupun bahan ajar yang digunakan di sekolah sembilan filum Animalia dibahas satu persatu. Kelemahan dari pembahasan filum secara satu persatu adalah siswa tidak dapat membandingkan persamaan ataupun perbedaan antarfilum dan cenderung lupa dengan pembahasan filum sebelumnya.

d) Mengacu pada Kurikulum 2013

Kurikulum 2013 mengamanatkan agar pembelajaran yang dilakukan berpusat pada siswa dan pembelajaran yang aktif. Modul Animalia kontekstual berbasis LoI memiliki aktivitas belajar sesuai sintaks LoI yang berpusat pada siswa dan menuntut siswa aktif menggunakan kemampuan berpikirnya. Kegiatan belajar tersebut disusun berdasarkan indikator ketercapaian kompetensi yang diturunkan dari KI dan KD dalam Kurikulum 2013.

e) Bersifat kontekstual

Modul Animalia kontekstual berbasis LoI dirancang dan dikembangkan dengan mengaitkan antara materi dengan situasi dunia nyata, dan mendorong siswa membuat hubungan antara pengetahuan yang dimiliki dengan penerapan dalam kehidupan sehari-hari. Belajar kontekstual akan terjadi apabila siswa memproses informasi atau pengetahuan baru sedemikian rupa sehingga dapat dipahami dalam kerangka acuan (memori, pengalaman, dan respon) dari siswa sendiri (Raub, Shukor, Arshad, \& Rosli, 2015). Modul Animalia kontekstual berbasis LoI menggunakan contohcontoh Animalia yang dapat dijumpai siswa di sekitar lingkungannya yaitu wilayah pesisir Gunungkidul.

Pesisir selatan Gunungkidul mempunyai keanekaragaman hewan akuatik maupun terestrial. Hewan akuatik yang mendominasi adalah invertebrata yang berhabitat di daerah pesisir antara lain berbagai spesies kepiting, polychaeta, landak laut, bintang laut, siput laut, dan kerang (Hadiyanto, 2012; Herawati, Rudi, \& Betty, 2012; Hudafi'ah, 2014; Pujiastuti, 2012). Sedangkan hewan terestrial khas daerah pesisir selatan didominasi oleh kelas aves (Untung, 2012).

Pembelajaran menggunakan modul Animalia kontekstual berbasis LoI dapat mengubah pembelajaran yang berpusat pada guru menjadi berpusat pada siswa. Pembelajaran yang berpusat pada siswa mendorong siswa untuk aktif mencari pengetahuan sendiri karena pada dasarnya belajar merupakan proses siswa dalam membangun pengetahuannya sendiri melalui berbagai stimulus dan daya dukung. Hal tersebut sejalan dengan teori belajar Bruner yang menyatakan bahwa belajar adalah proses yang aktif yaitu siswa membangun sendiri pengetahuan yang dimiliki (Dahar, 2011).

Penggunaan modul Animalia kontekstual berbasis LoI juga memfasilitasi siswa untuk mempelajari materi Animalia yang dikaitkan dengan situasi dunia nyata siswa. Siswa didorong untuk membuat hubungan antara pengetahuan yang dimiliki dengan kehidupan nyata siswa sehingga siswa dapat memahami materi Animalia yang dipelajari dengan baik dan mudah. Hal tersebut sejalan dengan teori belajar Ausubel dan pembelajaran kontekstual yang menyatakan bahwa pembelajaran bermakna bagi siswa apabila siswa mengaitkan pengetahuan yang sudah ada ke dalam pengetahuan baru yang sesuai dengan struktur kognitifnya (Dahar, 2011; Kamariah \& Rashid, 2011).

Struktur kognitif yang sesuai dengan siswa di SMA A kecamatan Tanjungsari yaitu contoh-contoh animalia yang sering dijumpai di wilayah pesisir Gunungkidul. Sejalan dengan penelitian yang dilakukan oleh Suratsih (2010) bahwa siswa lebih mudah mengaplikasikan pengetahuan yang dimiliki dalam situasi dan kondisi yang lain apabila materi 
yang dipelajari berkaitan langsung dengan pengalaman sehari-hari. Pembelajaran yang dikaitkan dengan pengalaman sehari-hari tersebut berkontribusi dalam mengurangi terjadinya miskonsepsi siswa dalam mempelajari materi Animalia.

Modul Animalia kontekstual berbasis LoI melatih siswa dalam berpikir untuk menyelesaikan permasalahan tidak hanya terbatas pada konteks modul saja, tetapi juga permasalahan lain yang ada hubungannya dengan kehidupan sehari-hari. Permasalahan tersebut menuntut siswa untuk mencari cara penyelesaiannya dengan berbagai cara, seperti mengamati, menguraikan permasalahan, membuat prediksi, menelusuri data untuk mengungkap fakta, dan menyimpulkan penyelesaian. Oleh karena itu, siswa akan melakukan proses berpikir ilmiah secara kritis terutama pada kemampuan menganalisis argumen dan mengenali alasan serta pernyataan (Facione, 2013). Proses berpikir tersebut harus dilalui siswa untuk membekali dalam kehidupannya kelak di masyarakat.

\section{Simpulan}

Kesimpulan hasil penelitian ini adalah modul Animalia kontekstual berbasis LoI layak untuk digunakan dalam pembelajaran biologi di SMA wilayah pesisir. Modul tersebut memiliki karakteristik modul sains, berbasis model LoI, dikembangkan pada materi Animalia, mengacu pada K-13, dan bersifat kontekstual.

\section{Daftar Pustaka}

Balım, A. G. (2009). The effects of discovery learning on students' success and inquiry learning skills. Eurasian Journal of Educational Research, 35(35), 1-20.

Borg, W. R., \& Gall, M. D. (I983). Educational research: An introduction. New York: Logman Publishing.

Dahar, R. W. (2011). Teori-teori belajar dan pembelajaran. Bandung: Erlangga.

Daryanto. (2013). Menyusun modul bahan ajar untuk persiapan guru dalam mengajar. Yogyakarta: Gava Media.

Facione, P. A. (2013). Critical thinking: What it is and why it counts. Insight assessment.

Garbett, D. (2011). Constructivism deconstructed in science teacher education. Australian Journal of Teacher Education, 36(6). http://dx.doi.org/10.14221/ajte.2011v36n6.5
Hadiyanto. (2012). Taxonomic notes of cryptic polychaeta on the seaweed in rocky intertidal shores of Gunungkidul Yogyakarta. In Seminar Nasional Taksonomi Fauna ke IV UNSOED. Purwokerto: UNSOED.

Herawati, P., Rudi, N., \& Betty, R. (2012). Portunidae crabs (Decapoda; Brachyura; Portunidae) from coastal area of Gunungkidul regency Yogyakarta Indonesia. In Seminar Nasional Taksonomi Fauna ke IV UNSOED. Purwokerto: UNSOED.

Hudafíah, N. (2014). Keanekaragaman Echinodermata di daerah pasang-surut pantai Ngandong dan Sadranan, Gunungkidul, Yogyakarta. Universitas Negeri Yogyakarta.

Kamariah, N., \& Rashid, W. M. (2011). A study of the effectiveness of the contextual approach to teaching and learning statistics at the Universiti Tun Hussein On Malaysia (UTHM). International Journal Of Arts \& Sciences, 4(25), 305-313.

Mackovjaková, Z., \& Ješková, Z. (2014). Using interactive demonstrations at Slovak secondary schools. Thinking Assessment in Science and Mathematics, (135).

Mulyasa, E. (2005). Menjadi guru profesional menciptakan pembelajaran kreatif dan menyenangkan. Bandung: Remaja Rosdakarya.

Oral, Ş. B. (2012). Providing a rationale for promoting argument-based inquiry approach to science education: A deweyan pragmatist aesthetics perspective. Melvana International Journal of Education (MIJE), $2(3), 69-78$.

Praptiwi, L., Sarwi, \& Handayani, L. (2012). Efektivitas model pembelajaran eksperimen inkuiri terbimbing berbantuan my own dictionary untuk meningkatkan penguasaan konsep dan unjuk kerja siswa SMP RSBI. Unnes Science Education Journal, 1(2).

Prastowo, A. (2012). Panduan kreatif membuat bahan ajar inovatif. Yogyakarta: Diva Press.

Pujiastuti, P. (2012). Pemanfaatan secara lestari kawasan Perairan pantai Krakal sebagai sarana pembelajaran. Yogyakarta: Universitas Negeri Yogyakarta.

Raub, L. A., Shukor, N. A., Arshad, M. Y., \& Rosli, M. S. (2015). An integrated model to implement contextual learning with virtual 
learning environment for promoting higher order thinking skills in Malaysian secondary schools. International Education Studies, $8(13)$,

41. https://doi.org/10.5539/ies.v8n13p41

Rusche, S. N., \& Jason, K. (2011). "You have to absorb yourself in it" using inquiry and reflection to promote student learning and self-knowledge. Teaching Sociology, 39(4), 338-353.

https://doi.org/10.1177/0092055X11418685

Sukirman. (2012). Pengembangan media pembelajaran. Yogyakarta: Pedagogia.

Suratsih. (2010). Pengembangan modul pembelajaran biologi berbasis potensi lokal dalam kerangka implementasi KTSP SMA di Yogyakarta. Yogyakarta.
Suwondo, Febrita, E., \& Suryana, A. (2013). Analisis aktivitas dan sikap ilmiah mahasiswa dengan model pengajaran langsung berbasis inkuiri pada mata kuliah sistematika invertebrata. Jurnal Biogenesis, 10(1), 1-10.

Toharudin, U., Hendrawati, S., \& Rustaman, A. (2011). Membangun literasi sains peserta didik. Bandung: Humaniora.

Untung, M. (2012). Keanekaragaman jenis dan kelimpahan burung di kawasan pantai karst Gunungsewu. In Seminar Nasional Taksonomi Fauna ke IV UNSOED. Purwokerto: UNSOED.

Wenning, C. J. (2011). The levels of inquiry model of science teaching. Journal of Physics Teacher Education Online, 6(2), 9-16. 